\title{
Hypergolic Ignition of 1,3-Cyclodienes by Fuming Nitric Acid toward the Fast and Spontaneous Formation of Carbon Nanosheets at Ambient Conditions
}

\author{
Nikolaos Chalmpes ${ }^{1}$ (D), Dimitrios Moschovas ${ }^{1}$, Athanasios B. Bourlinos ${ }^{2, *}$, Konstantinos Spyrou ${ }^{1}$ (D), \\ Konstantinos C. Vasilopoulos ${ }^{1} \mathbb{D}$, Apostolos Avgeropoulos ${ }^{1} \mathbb{D}$, Michael A. Karakassides ${ }^{1} \mathbb{D}$ \\ and Dimitrios Gournis ${ }^{1, *(D)}$
}

1 Department of Materials Science \& Engineering, University of Ioannina, 45110 Ioannina, Greece; chalmpesnikos@gmail.com (N.C.); dmoschov@uoi.gr (D.M.); konstantinos.spyrou1@gmail.com (K.S.); kovasil@auth.gr (K.C.V.); aavger@uoi.gr (A.A.); mkarakas@uoi.gr (M.A.K.)

2 Physics Department, University of Ioannina, 45110 Ioannina, Greece

* Correspondence: bourlino@uoi.gr (A.B.B.); dgourni@uoi.gr (D.G.); Tel.: +30-26510-08511 (A.B.B.); +30-26510-07141 (D.G.)

check for updates

Citation: Chalmpes, N.; Moschovas,

D.; Bourlinos, A.B.; Spyrou, K.;

Vasilopoulos, K.C.; Avgeropoulos, A.; Karakassides, M.A.; Gournis, D.

Hypergolic Ignition of

1,3-Cyclodienes by Fuming Nitric

Acid toward the Fast and

Spontaneous Formation of Carbon Nanosheets at Ambient Conditions. Micro 2021, 1, 15-27.

https: / / doi.org/

10.3390/micro1010003

Academic Editor: Ewa Kowalska

Received: 3 April 2021

Accepted: 14 May 2021

Published: 18 May 2021

Publisher's Note: MDPI stays neutral with regard to jurisdictional claims in published maps and institutional affiliations.

Copyright: (c) 2021 by the authors. Licensee MDPI, Basel, Switzerland. This article is an open access article distributed under the terms and conditions of the Creative Commons Attribution (CC BY) license (https:/ / creativecommons.org/licenses/by/ $4.0 /)$.

\begin{abstract}
A hypergolic system is a combination of organic fuel and oxidizer that ignites spontaneously upon contact without any external ignition source. Although their main usage pertains to rocket bipropellants, it is only recently that hypergolics have been established from our group as a revolutionary preparative method for the synthesis of different types of carbon nanostructures depending on the organic fuel-oxidizer pair. In an effort to further enrich this concept, the present work describes new hypergolic pairs based on 1,3-cyclohexadiene and 1,3-cyclooctadiene as the organic fuels and fuming nitric acid as the strong oxidizer. Both carbon-rich compounds (ca. $90 \%$ C) share a similar chemical structure with unsaturated cyclopentadiene that is also known to react hypergolically with fuming nitric acid. The particular pairs ignite spontaneously upon contact of the reagents at ambient conditions to produce carbon nanosheets in suitable yields and useful energy in the process. The nanosheets appear amorphous with an average thickness of $c a .2 \mathrm{~nm}$ and containing $\mathrm{O}$ and $\mathrm{N}$ heteroatoms in the carbon matrix. Worth noting, the carbon yield reaches the value of $25 \%$ for 1,3-cyclooctadiene, i.e., the highest reported so far from our group in this context. As far as the production of useful energy is concerned, the hot flame produced from ignition can be used for the direct thermal decomposition of ammonium dichromate into $\mathrm{Cr}_{2} \mathrm{O}_{3}$ (pigment and catalyst) or the expansion of expandable graphite into foam (absorbent and insulator), thus demonstrating a mini flame-pyrolysis burner at the spot.
\end{abstract}

Keywords: hypergolic reaction; carbon nanosheets; 1,3-cyclohexadiene; 1,3-cyclooctadiene; fuming nitric acid; useful chemical energy

\section{Introduction}

Carbon plays a fundamental role in materials science due to its ability to exist in various forms and morphologies possessing outstanding properties [1-4]. Traditionally, the making of carbon is often an energy-consuming process that requires high temperature in order to extract the element from its compounds. However, is it possible to make carbon at ambient conditions in an energy-liberating manner? Hypergolics may hold the key to this question. In hypergolics, a fuel and an oxidizer ignite spontaneously upon contact without external stimuli. Although the concept is widely used in space flights and the rocket industry for several decades now [5-8], it is only recently that their role in carbon materials synthesis has been explored by our group [9-16].

More specifically, carbon nanosheets had been previously obtained from self-ignition of lithium dialkylamides in air [9], highly crystalline graphite through the spontaneous 
reaction of the acetylene-chlorine hypergolic mixture [10], carbon dots or nanosheets via hypergolic pairs based on Girard's reagent $\mathrm{T}$ or nitrile rubber and fuming nitric acid as strong oxidizer [11], carbon nanosheets or hydroxylated fullerenes using coffee grains or $\mathrm{C}_{60}$ as carbon sources and sodium peroxide as strong oxidizer [12], dense or hollow spheres derived from the reaction of ferrocene with liquid bromine at room temperature [13], carbon nanodiscs obtained through the cyclopentadienyllithium-fuming nitric acid hypergolic pair [14], carbon nanosheets via the hypergolic reaction of furfuryl alcohol with fuming nitric acid at ambient conditions [15], and lastly, carbon nanosheets or carbon dots from the hypergolic ignition of conductive polymers [16]. The new synthesis method not only allows the fast and spontaneous formation of the above-mentioned nanocarbons at ambient conditions but also produces useful energy in the process, such as chemical, mechanical, thermoelectric, photovoltaic, or heating fluids. At this point, we would like to mention that the exothermic character of the hypergolic reactions in combination with the release of gases provides spontaneity (e.g., $\Delta \mathrm{H}<0$ and $\Delta \mathrm{S}>0$ give $\Delta \mathrm{G}=\Delta \mathrm{H}-\mathrm{T} \cdot \Delta \mathrm{S}<0$ ), whereas the fast kinetics probably stems from the fact that hypergolic reactions are usually spin allowed (e.g., the change of spin is zero as moving from diamagnetic reactants to diamagnetic products). The spontaneity and fast kinetics at ambient conditions clearly differentiate from conventional pyrolytic approaches that require energy and time in order to extract carbon from its compounds.

Since hypergolic materials synthesis is a fresh preparative technique in material science at its infancy stage, our first priority is to further explore and study as many as possible chemical options in this direction. Hence, in a continuous search of new pairs in this context, herein we present the hypergolic ignition of 1,3-cyclohexadiene and 1,3-cyclooctadiene by fuming nitric acid toward the fast and spontaneous formation of carbon nanosheets at ambient conditions. The chosen organic compounds, which contain high carbon contents $(90 \%)$, can be regarded as a rational extension of the simplest unsaturated prototype cyclopentadiene presented elsewhere [14]. At the same time, we provide simple ways of converting the released energy into useful chemical work. For instance, the produced flame can be used for the direct thermal decomposition of ammonium dichromate into $\mathrm{Cr}_{2} \mathrm{O}_{3}$ or the thermal expansion of graphite bisulfate (expandable graphite) into foam, thus demonstrating a sort of mini flame-pyrolysis burner sustained by hypergolic reactions. Lastly, it is worth mentioning the fact that the carbon yield for the 1,3 -cyclooctadiene- $-\mathrm{HNO}_{3}$ pair is $25 \%$, i.e., the highest reported so far using hypergolics (usually $5-15 \%$ ).

\section{Materials and Methods}

All procedures were performed in a safety hood with a ceramic tile bench using a small number of reagents.

A glass test tube (diameter: $1.5 \mathrm{~cm}$; length: $15 \mathrm{~cm}$ ) was charged with $0.5 \mathrm{~mL} 1,3-$ cyclohexadiene ( $97 \% \mathrm{C}_{6} \mathrm{H}_{8}$, Sigma-Aldrich, CAS Number: 592-57-4, St. Louis, MO, USA) followed by the dropwise addition of $0.25 \mathrm{~mL}$ fuming nitric acid $(100 \%$, Sigma-Aldrich, St. Louis, MO, USA). The addition of fuming nitric acid triggered ignition toward the formation of a carbon residue within the test tube. The residue was collected and washed thoroughly with acetone ( $\geq 99 \%$ Merck KGaA, Darmstadt, Germany), tetrahydrofuran (THF, $\geq 99 \%$ Merck KGaA, Darmstadt, Germany), and hexane ( $\geq 99 \%$ Merck KGaA, Darmstadt, Germany) prior to drying at $100^{\circ} \mathrm{C}$. A fine carbon powder was obtained (codenamed CDNA) at $7 \%$ yield $\left(\mathrm{N}_{2}\right.$ specific surface area: $27 \mathrm{~m}^{2} \mathrm{~g}^{-1}$ ). The ignition process is illustrated in Figure 1. 


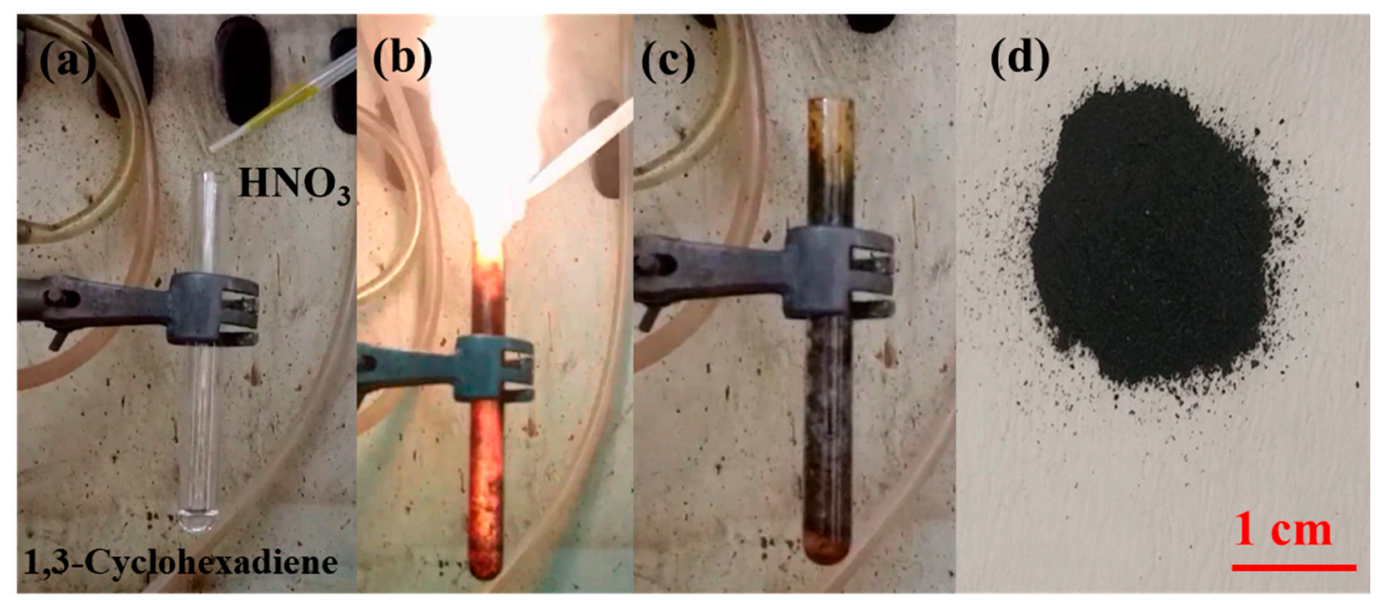

Figure 1. Hypergolic ignition of 1,3-cyclohexadiene by fuming nitric acid. (a) The test tube containing 1,3-cyclohexadiene before nitric acid addition. (b) Dropwise addition of the acid sparked ignition, emitting an intense burst of flame. (c,d) The residue within the tube was collected and washed thoroughly to afford a fine carbon powder.

Similarly, $0.5 \mathrm{~mL}$ 1,3-cyclooctadiene ( $\geq 95 \% \mathrm{C}_{8} \mathrm{H}_{12}$, Sigma-Aldrich, CAS Number: 1700-10-3, St. Louis, MO, USA) was charged in a test tube (diameter: $1.5 \mathrm{~cm}$; length: $15 \mathrm{~cm}$ ) followed by the dropwise addition of $0.5 \mathrm{~mL}$ fuming nitric acid (100\%, Sigma-Aldrich, St. Louis, MO, USA). The compound was ignited with a delay releasing an intense flame (Figure 2). The product was scratched off the walls of the test tube and then thoroughly washed with acetone ( $\geq 99 \%$ Merck KGaA, Darmstadt, Germany), tetrahydrofuran (THF, $\geq 99 \%$, Merck KGaA, Darmstadt, Germany), and hexane ( $\geq 99 \%$ Merck KGaA, Darmstadt, Germany) prior to drying at $100{ }^{\circ} \mathrm{C}$. A fine carbon powder was obtained (codenamed CONA) at $25 \%$ yield ( $\mathrm{N}_{2}$ specific surface area: $43 \mathrm{~m}^{2} \mathrm{~g}^{-1}$ ). This carbon yield is the highest reported so far from our group using hypergolic reactions (typically in the range of 5-15\%). It is likely that the less volatile nature of 1,3-cyclooctadiene (normal boiling point $140^{\circ} \mathrm{C}$ ) vs. 1,3-cyclohexadiene (normal boiling point $80^{\circ} \mathrm{C}$ ) prevents the compound from escaping the tube during ignition.

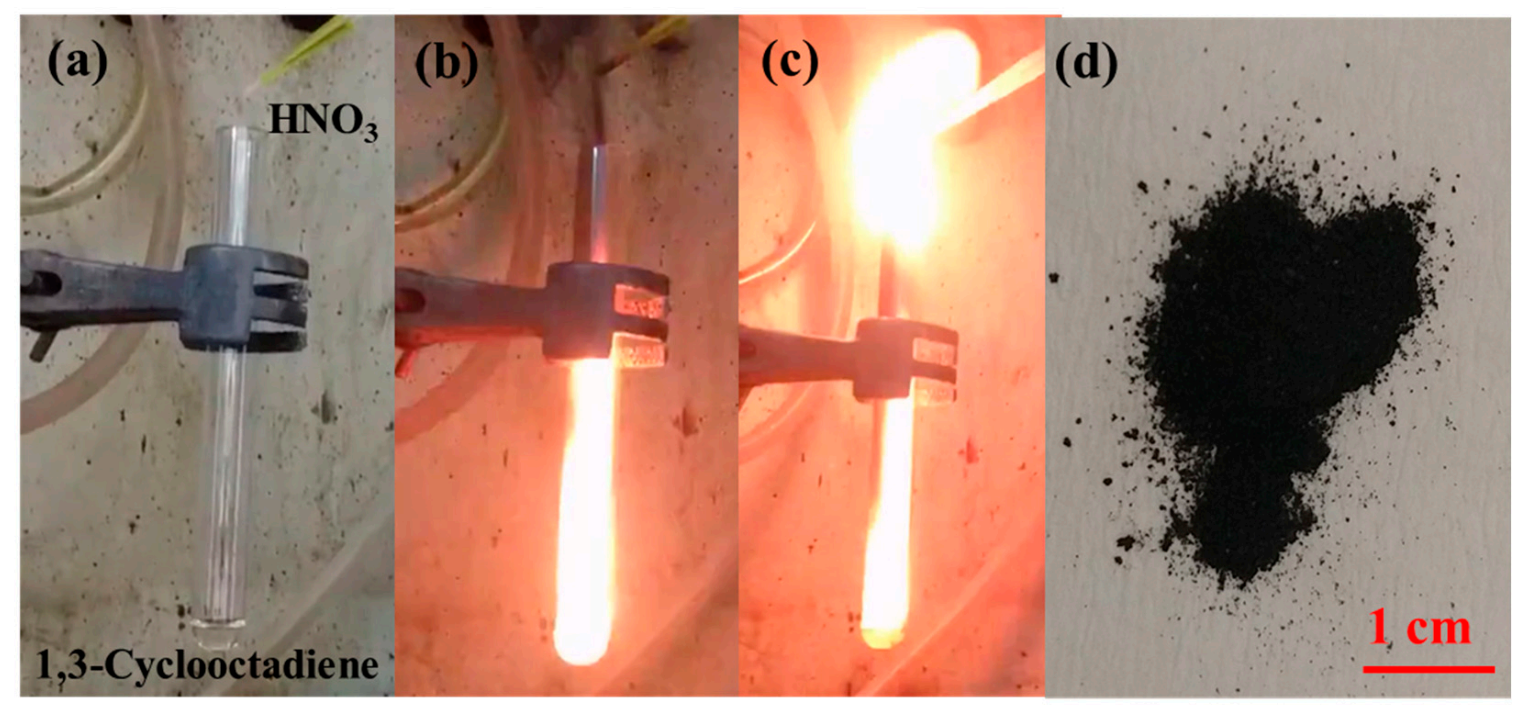

Figure 2. Hypergolic ignition of 1,3-cyclooctadiene by fuming nitric acid. (a) The test tube containing 1,3-cyclooctadiene before nitric acid addition. (b,c) Dropwise addition of the acid triggered ignition, giving off an intense burst of flame. The residue within the tube was collected and washed several times until a fine carbon powder was obtained (d). 
Powder X-ray diffraction (XRD) was performed using background-free Si wafers and $\mathrm{Cu} \mathrm{K} \alpha$ radiation from a Bruker Advance D8 diffractometer (Bruker, Billerica, MA, USA). Raman spectra were obtained on a DXR Raman microscope using a laser excitation line at $455 \mathrm{~nm}, 2 \mathrm{~mW}$ (Thermo Scientific Waltham, MA, USA). Optical spectroscopy was conducted with a UV/Vis spectrophotometer SPECORD S 600 operated by WinASPECT software. Attenuated total reflection infrared spectrum (ATR-IR) was recorded on a Thermo Nicolet iS5 FTIR spectrometer, using the Smart Orbit ZnSe ATR accessory. X-ray photoelectron spectroscopy (XPS) measurements were performed in an ultra-high vacuum at a base pressure of $4 \times 10^{-10}$ mbar with a SPECS GmbH spectrometer equipped with a monochromatic $\mathrm{Mg} \mathrm{K} \alpha$ source (hv $=1253.6 \mathrm{eV}$ and a Phoibos-100 hemispherical analyzer (Berlin, Germany). The spectral analysis included a Shirley background subtraction and peak deconvolution with mixed Gaussian-Lorentzian functions using a least-squares curvefitting program (WinSpec, University of Namur, Belgium). Scanning electron microscopy (SEM) images were obtained using a JEOL JSM-6510 LV SEM Microscope (Ltd., Tokyo, Japan) equipped with an X-Act EDS-detector by Oxford Instruments, Abingdon, Oxfordshire, U.K. $(5 \mathrm{kV})$. Transmission electron microscopy (TEM) analysis was performed on JEOL JEM 2100 at $200 \mathrm{kV}$ using a LaB6 type emission gun. Atomic force microscopy (AFM) images were collected in tapping mode with a Bruker Multimode 3D Nanoscope (Ted Pella Inc., Redding, CA, USA) using a microfabricated silicon cantilever type TAP-300G, with a tip radius of $<10 \mathrm{~nm}$ and a force constant of approximately $20-75 \mathrm{~N} \mathrm{~m}^{-1}$. The Si wafers ( $\mathrm{P} /$ Bor, single-side polished, Si-Mat) used in AFM imaging were cleaned before use for $20 \mathrm{~min}$ in an ultrasonic bath $(160 \mathrm{~W})$ with water, acetone ( $\geq 99.5 \%$ Sigma-Aldrich, St. Louis, MO, USA), and ethanol ( $\geq 99.5 \%$ Sigma-Aldrich, St. Louis, MO, USA).

\section{Results and Discussion}

The carbon obtained from the 1,3-cyclodiene- $\mathrm{HNO}_{3}$ hypergolic pairs was identified by the XRD and Raman techniques. The XRD patterns of CDNA and CONA exhibited, respectively, broad reflections at $\mathrm{d}_{002}=0.42 \mathrm{~nm}$ and $\mathrm{d}_{002}=0.46 \mathrm{~nm}$ (Figure 3 , top), thus signaling the formation of amorphous carbon [17]. Raman spectroscopy (Figure 3, bottom) revealed the typical for carbon materials $\mathrm{G}$ and $\mathrm{D}$ bands [18], also indicating the formation of amorphous carbon. The samples additionally displayed a strong yet broad band at $2900 \mathrm{~cm}^{-1}$, indicative of nitrogen incorporation into the carbon lattice [19].

The ATR-IR spectra of the solids are shown in Figure 4, top. In the case of CDNA, the peaks at 1717 and $1616 \mathrm{~cm}^{-1}$ are assigned to the corresponding $\mathrm{C}=\mathrm{O}$ and $\mathrm{C}=\mathrm{C}$ stretchings [20]. The intense band at $1507 \mathrm{~cm}^{-1}$ and the weak shoulder at $c a .1300 \mathrm{~cm}^{-1}$ originate from $\mathrm{C}=\mathrm{N}$ and $\mathrm{C}-\mathrm{O}$ moieties, respectively, whereas the band at $1102 \mathrm{~cm}^{-1}$ stems from $\mathrm{C}-\mathrm{N}-$ $\mathrm{C}$ bending vibrations. The peak at $780 \mathrm{~cm}^{-1}$ is correlated with the bending modes of $\mathrm{C}-\mathrm{H}$. The material additionally contains aliphatic hydrogens, as evidenced by the stretching of the $\mathrm{C}-\mathrm{H}$ group near $3000 \mathrm{~cm}^{-1}$ along with the stretching vibrations of $\mathrm{N}-\mathrm{H},-\mathrm{OH}$ in the high region frequencies [21]. On the other hand, CONA displayed similar absorptions bands with CDNA. The weak peaks near $3000 \mathrm{~cm}^{-1}$ were assigned to residual $\mathrm{C}-\mathrm{H}$ moieties while the weak shoulder at $1705 \mathrm{~cm}^{-1}$ was assigned to carbonyl groups $\mathrm{C}=\mathrm{O}$. The broadband at ca. $1300 \mathrm{~cm}^{-1}$ was due to the $\mathrm{C}-\mathrm{O}$ stretching mode while those at $1539 \mathrm{~cm}^{-1}$ and $1619 \mathrm{~cm}^{-1}$ due to $\mathrm{C}=\mathrm{N}$ and $\mathrm{C}=\mathrm{C}$ bonds, respectively. The material additionally contains the bending modes of the $\mathrm{C}-\mathrm{H}$ group $\left(750 \mathrm{~cm}^{-1}\right)$. Lastly, the bands at $3250 \mathrm{~cm}^{-1}$ and $3400 \mathrm{~cm}^{-1}$ were ascribed to $\mathrm{N}-\mathrm{H}$ and $-\mathrm{OH}$ groups, respectively. As far as the UV-vis spectra of CDNA and CONA are concerned, these exhibit a well-discernable peak at $273 \mathrm{~nm}$ attributed to $\pi-\pi^{*}$ transitions within long-ranged $\mathrm{sp}^{2}$ domains (Figure 4, bottom) [22-24]. 

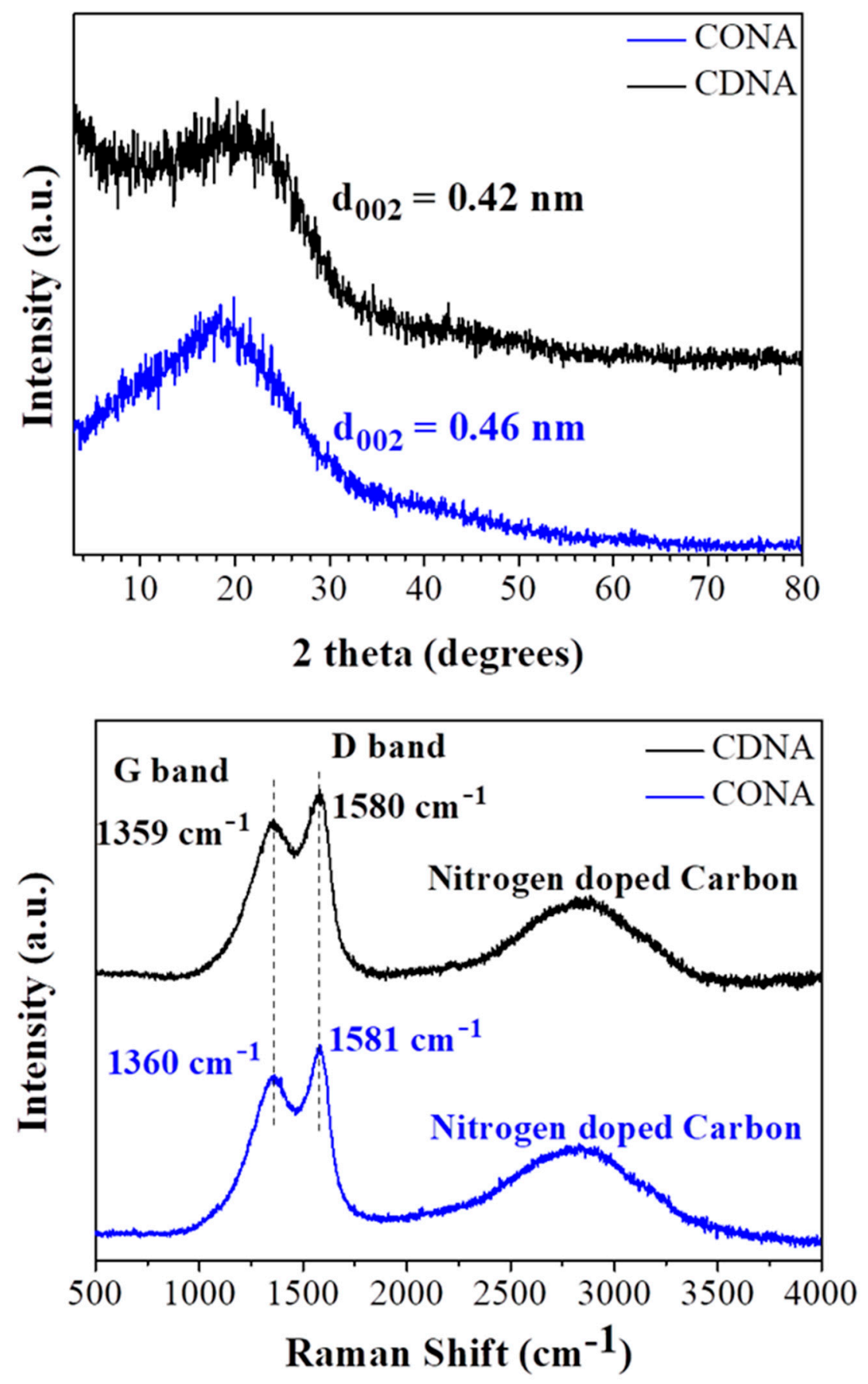

Figure 3. XRD patterns (top) and Raman spectra (bottom) of CDNA (black lines) and CONA (blue lines). 

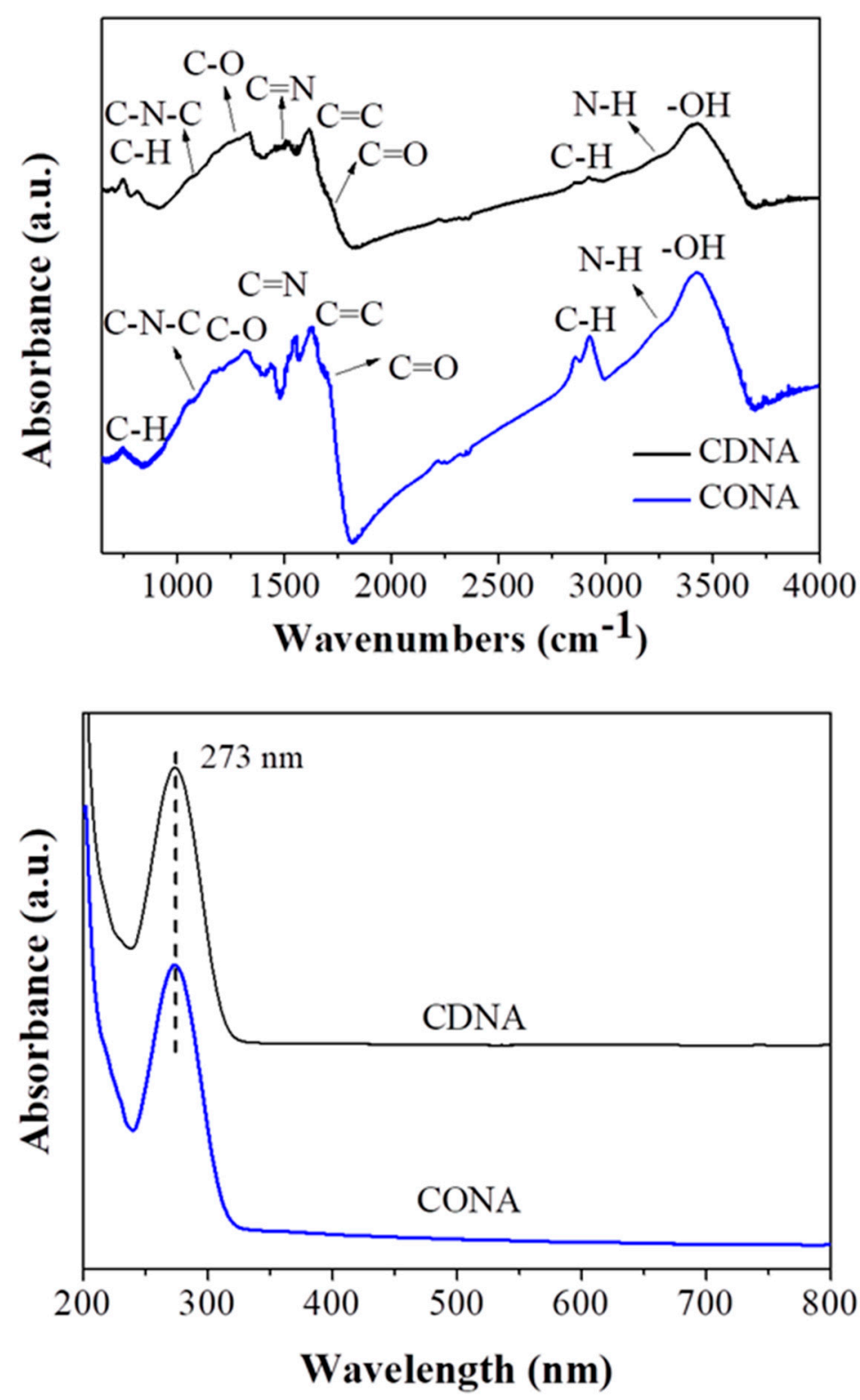

Figure 4. ATR-IR spectra (top) and UV-vis spectra (bottom) of CDNA (black lines) and CONA (blue lines).

The XPS technique was used in order to further clarify the chemical structure of the solids (Figure 5). The survey spectra clearly showed the presence of variable amounts of $\mathrm{C}, \mathrm{O}$, and $\mathrm{N}$ in the elemental composition of the samples. Characteristically, CDNA was more oxidized than CONA, with the corresponding carbon contents being $49.3 \%$ and $79.2 \%$ (note that both samples contained comparable amounts of nitrogen). The high-resolution C1s spectra of CDNA and CONA were deconvoluted into five components. The peak at $284.6 \mathrm{eVis}$ due to $\mathrm{C}-\mathrm{C} / \mathrm{C}-\mathrm{H} / \mathrm{C}=\mathrm{C}$ bonds. At $286.1 \mathrm{eV}$, we have the contribution from $\mathrm{C}-\mathrm{O} / \mathrm{C}-\mathrm{N}$ bonds, while at $287.1 \mathrm{eV}$ the contribution from $\mathrm{C}-\mathrm{O}-\mathrm{C} / \mathrm{C}=\mathrm{O}$ groups. The peak at higher binding energy $(288.4 \mathrm{eV})$ is due to carboxyl groups. We additionally observe a peak at even higher binding energies that reveals the graphitic nature of the samples due to pi-pi* interactions between aromatic groups [25]. Lastly, the deconvoluted N1s spectra showed that the nitrogen atoms were present mainly in two forms: pyrrolic at lower binding energies and quaternary at higher binding energies [26]. 

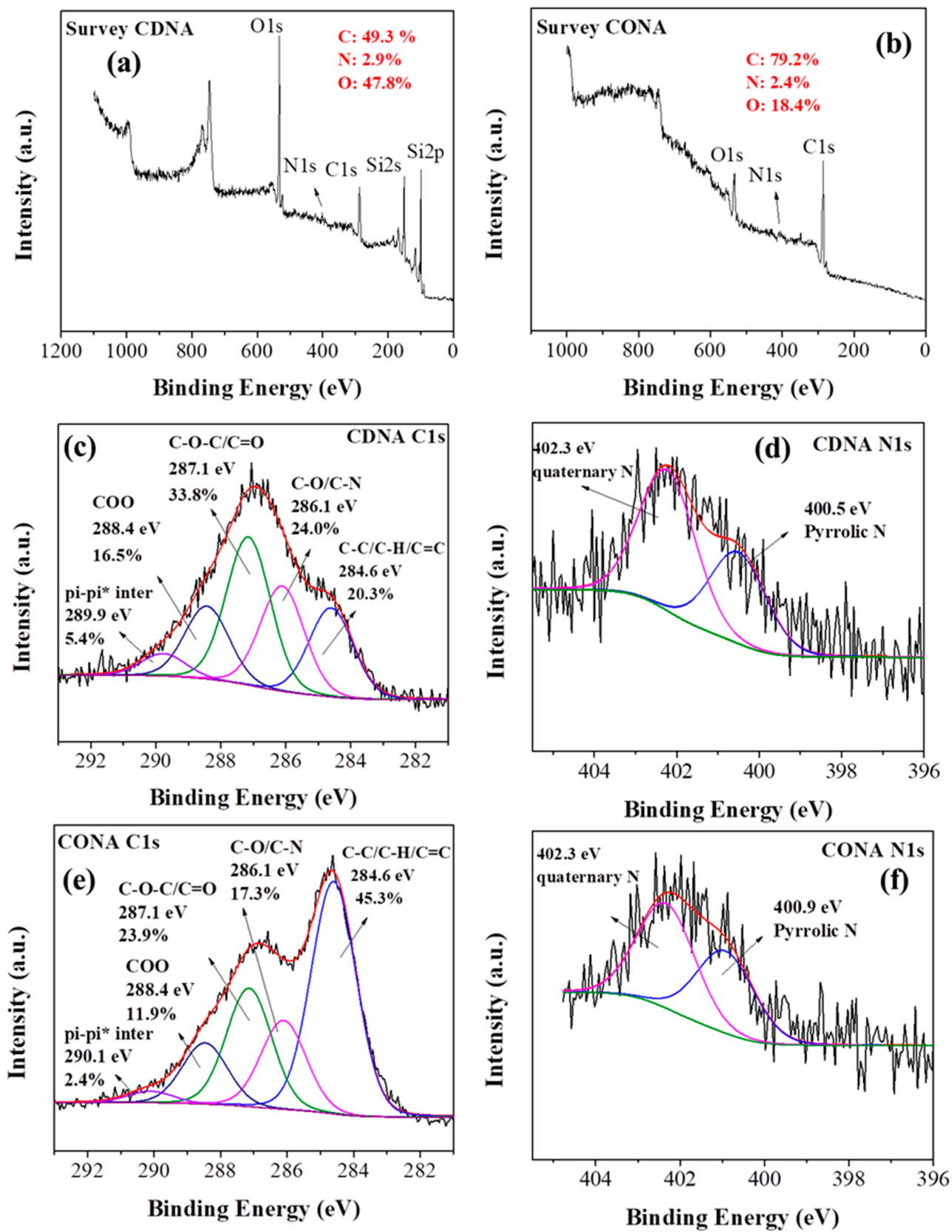

Figure 5. Survey, C1s and N1s photoelectron spectra of CDNA (a,c,d) and CONA (b,e,f).

The AFM study of CDNA and CONA clearly showed the formation of carbon nanosheets (Figure 6). The average thicknesses of the sheets as evaluated by AFM crosssectional images occupied the range of $1.8-2.5 \mathrm{~nm}$. To properly determine the nanosheets size distributions, a statistical analysis was performed based on AFM representative imaging. An amount of 30 randomly selected carbon nanostructures were used for the statistical analysis histograms. As a result, in thickness histograms, the Gaussian curves fit are centered on the average values of $2.0 \mathrm{~nm}$ for CDNA and $2.2 \mathrm{~nm}$ for CONA (Figure 7). 

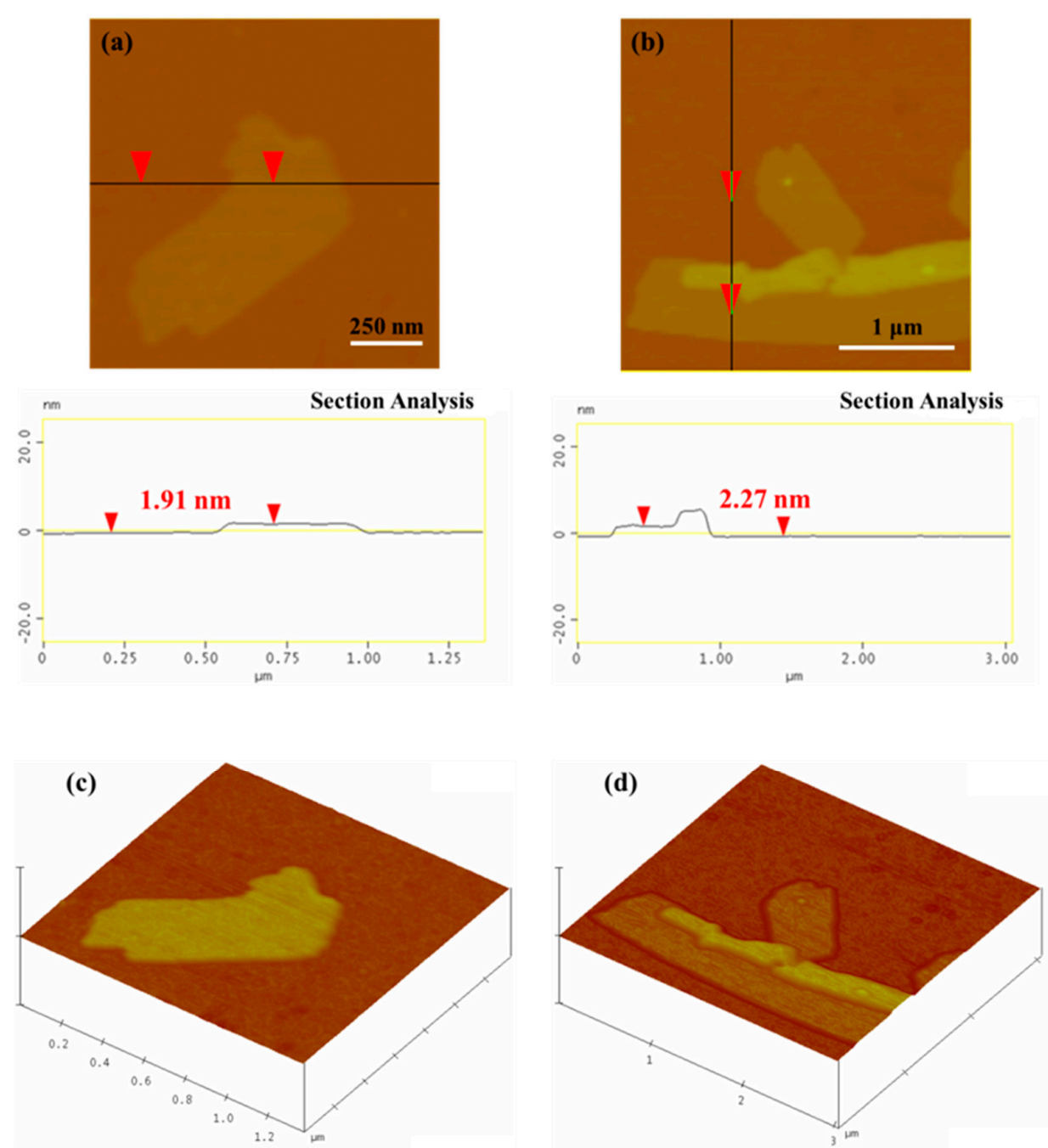

Figure 6. AFM images of cross-sectional analysis and 3D morphologies of CDNA (a,c) and CONA (b,d).
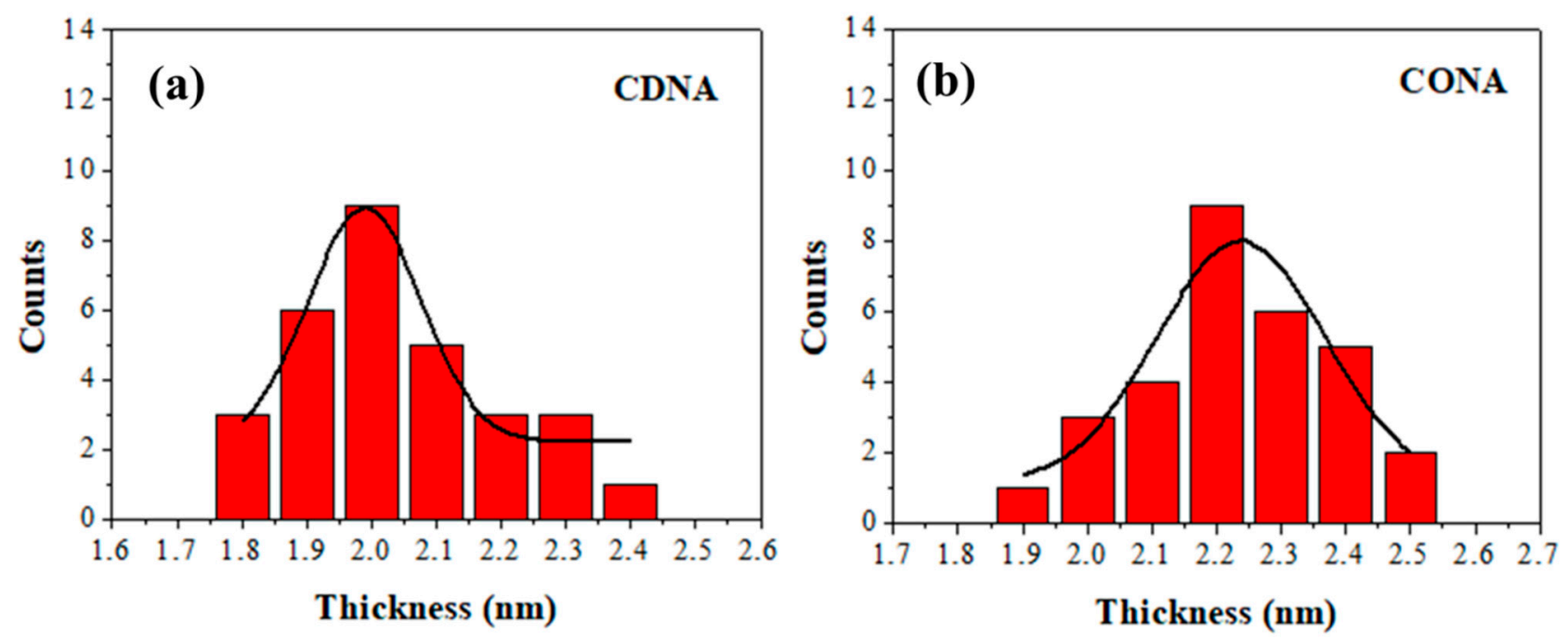

Figure 7. Statistical analysis histograms of thickness for CDNA (a) and CONA (b). 
The morphology of the samples was additionally confirmed by electron microscopy (Figure 8). Accordingly, the SEM and TEM portraits of CDNA and CONA revealed the presence of carbon nanosheets displaying multilayer structure near the edges due to stacks of individual layers.

At this point, we would like to mention that since the carbon precursors used in past preparations vary in structure and composition, it is difficult to make any direct comparison of the present findings with previous ones from our group. Each system is unique in terms of the obtained structure, composition, and morphology. Hence, any rational correlation between them would be rather misleading at this stage. We believe that only the closely related 1,3-cyclohexadiene and 1,3-cyclooctadiene can be discussed side-by-side in this work. Nevertheless, we could compare these 1,3-cyclodienes with the relevant cyclopentadienyllithium presented elsewhere [14]. Accordingly, the nanodiscs that had been previously obtained from cyclopentadienyllithium are morphologically different from the present nanosheets, although sharing a comparable structure and composition. This might be attributed to the starting cyclopentadiene ring, which generally favors the formation of round-shaped nanostructures. Another point refers to the carbon yields within this series of compounds, which increases as moving from cyclopentadienyllithium ( $2 \%$ ) to 1,3-cyclohexadiene (7\%) to 1,3-cyclooctadiene (25\%). Hence, the smaller yield for cyclopentadienyllithium can be ascribed to the relatively smaller carbon content of the compound, as well as its tendency to release cyclopentadiene gas upon acid treatment, which escapes from the reaction.
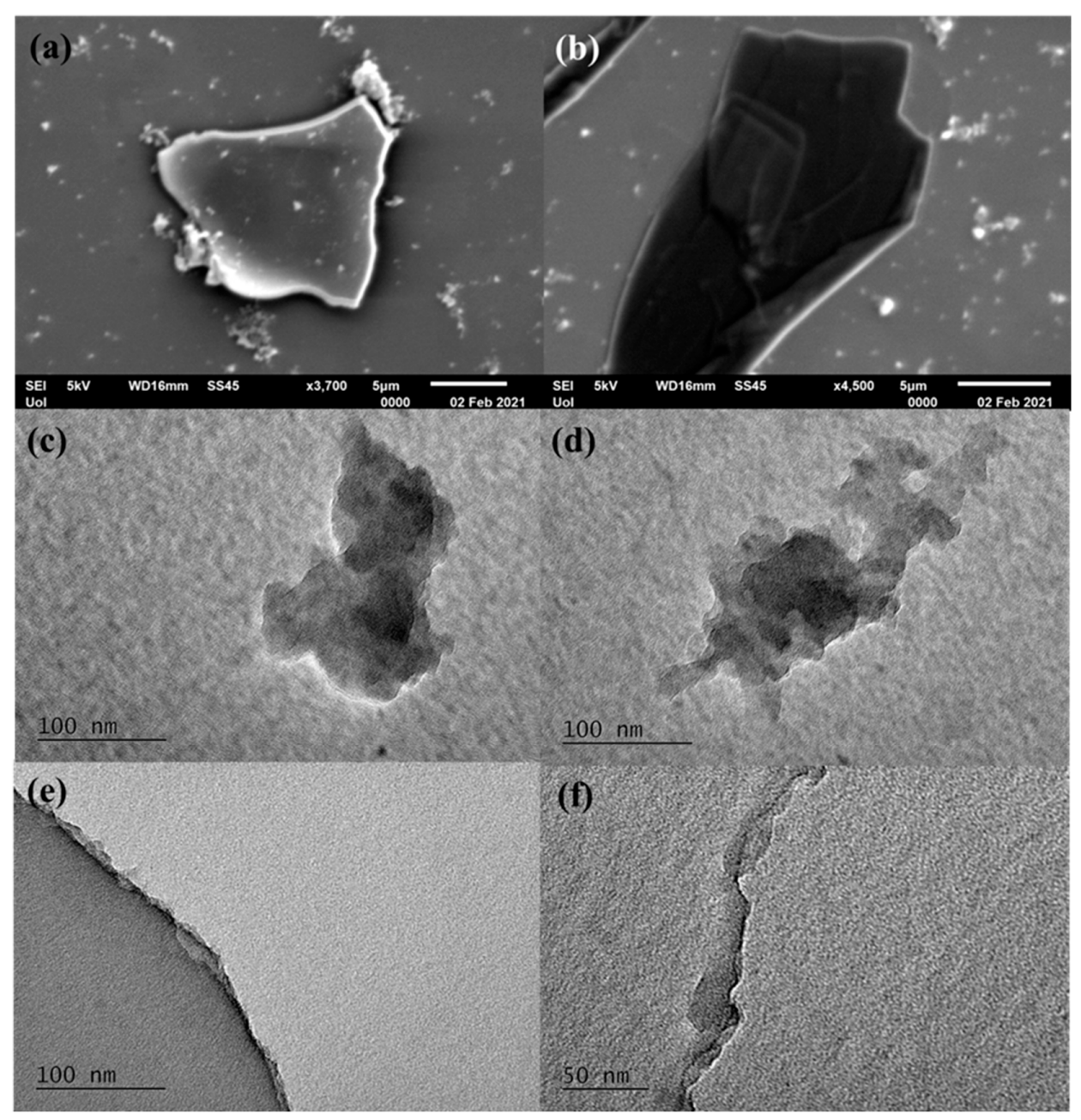

Figure 8. SEM and TEM images of CDNA $(\mathbf{a}, \mathbf{c}, \mathbf{e})$ and CONA $(\mathbf{b}, \mathbf{d}, \mathbf{f})$. 
The energy released from the hypergolic reactions was further exploited for the production of useful chemical work. In one example, the flame produced from the ignition of 1,3-cyclohexadiene was used for the thermal decomposition of ammonium dichromate into $\mathrm{Cr}_{2} \mathrm{O}_{3}$ (the "chemical volcano" experiment), thus representing a mini flame-pyrolysis burner set off by the hypergolic reaction (Figure 9). For this purpose, a metallic spatula loaded with ammonium dichromate was held above the top rim of the "rocket" test tube in direct contact with the released flame. $\mathrm{Cr}_{2} \mathrm{O}_{3}$ is a useful green pigment in the paint industry, as well as an efficient catalyst toward $\mathrm{NH}_{3}$ oxidation in the Ostwald process for making nitric acid.

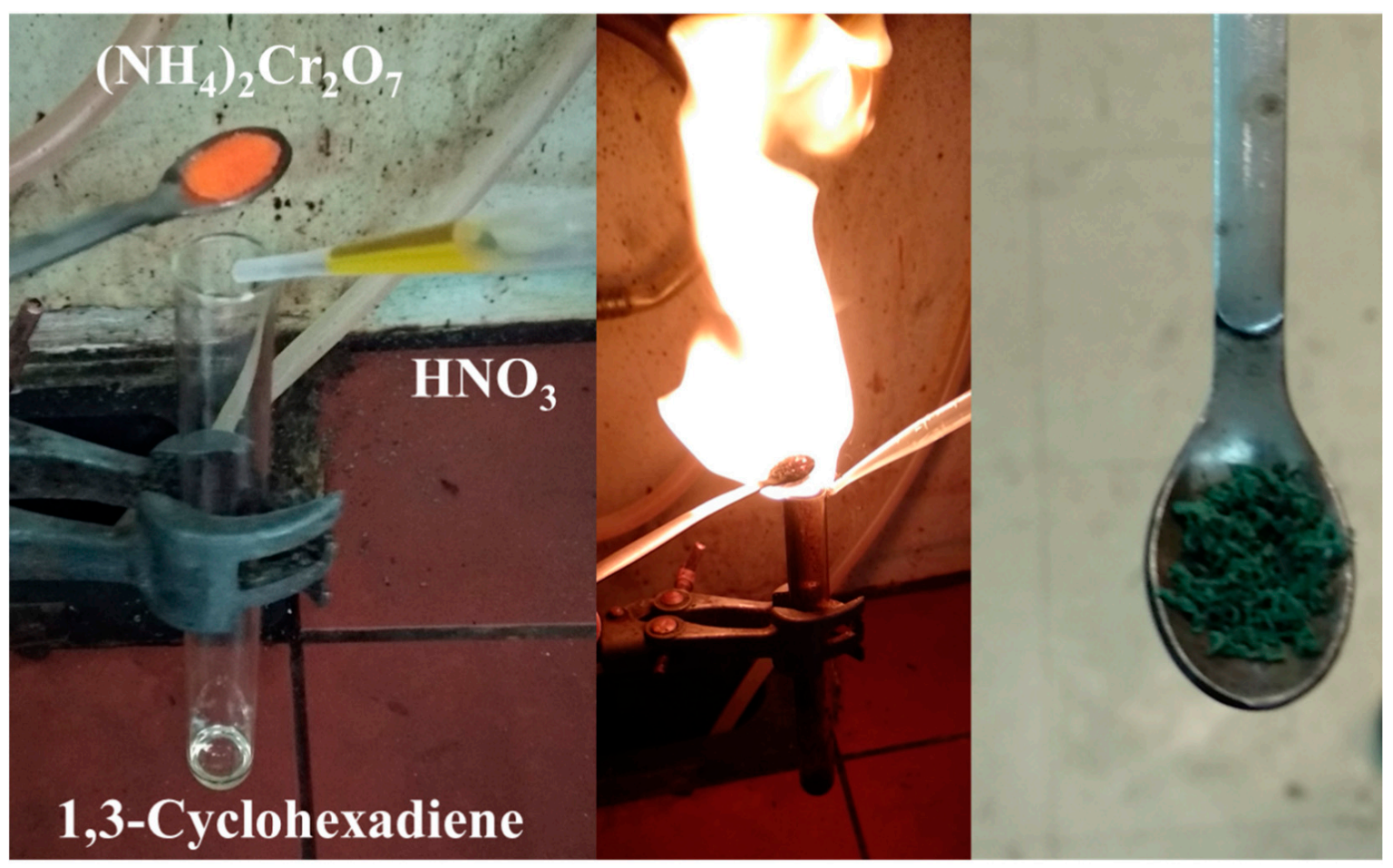

Figure 9. The flame produced from the ignition of 1,3-cyclohexadiene by fuming nitric acid was used for the thermal decomposition of ammonium dichromate $\left(\mathrm{NH}_{4}\right)_{2} \mathrm{Cr}_{2} \mathrm{O}_{7}$ (orange solid) into $\mathrm{Cr}_{2} \mathrm{O}_{3}$ pigment and catalyst (green solid).

In another example, the flame produced from the ignition of the 1,3-cyclooctadiene$\mathrm{HNO}_{3}$ pair was used to heat-expandable graphite (graphite bisulfate $\mathrm{C}_{24}{ }^{+} \mathrm{HSO}_{4}{ }^{-}$, SigmaAldrich, St. Louis, MO, USA) in an aluminum cup (Figure 10). Upon contact of the cup with the flame, the lustrous graphite flakes turned into foam. Such an expansion results from the thermal decomposition of the intercalated sulfate species into $\mathrm{SO}_{2}$ gas that pushes the graphite layers apart. The produced foam is considered an excellent absorbent material for oil removal, as well as a suitable thermal insulator and flame retardant. 


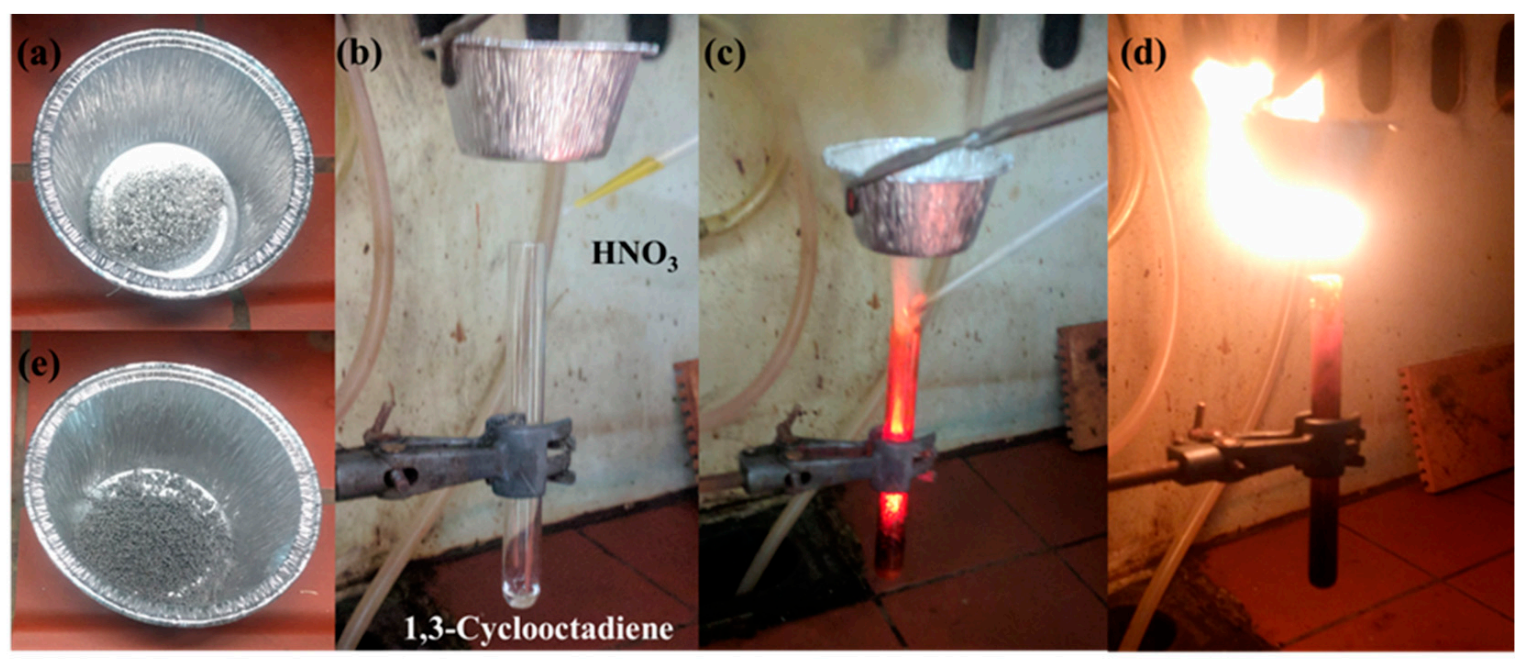

Figure 10. (a) The starting expandable graphite flakes in an aluminum cup. (b-d) The hypergolic reaction between 1,3-cyclooctadiene and fuming nitric acid provides the necessary heat for the thermal expansion of the flakes into foam (e).

It is interesting to note that poly(1,3-cyclohexadiene), which has been synthesized via anionic polymerization method under high vacuum techniques [27-31], also reacts hypergolically with fuming nitric acid (Figure 11), thus expanding the usage of the method beyond monomers' reactivity [16].

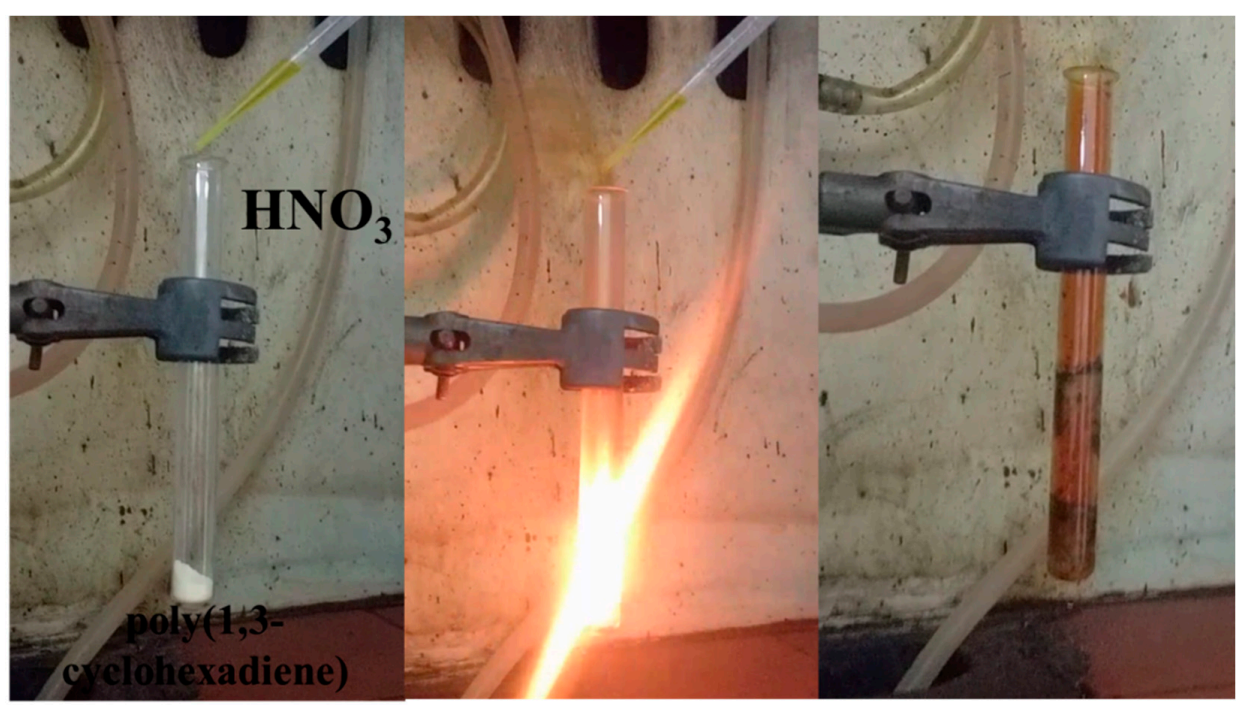

Figure 11. Dropwise addition of fuming nitric acid into poly(1,3-cyclohexadiene) triggers ignition of the polymer toward the formation of a carbon residue within the test tube.

\section{Conclusions}

The hypergolic synthesis of carbon nanomaterials is a new preparative technique in materials science, allowing synthesis at ambient conditions and releasing useful energy in the process. In exploring additional chemical options in this direction, we have demonstrated here that ignition of the carbon-rich compounds 1,3-cyclohexadiene and 1,3cyclooctadiene by fuming nitric acid leads to the fast and spontaneous formation of carbon nanosheets at ambient conditions in fairly suitable yields. In the case of 1,3-cyclooctadiene, the obtained carbon yield is the highest reported within this context, reaching the value of $25 \%$. The structure and morphology of the sheets were studied with a variety of techniques, such as XRD, infrared spectroscopies (Raman/IR), UV-vis, XPS, and SEM/TEM/AFM 
microscopies. The micron-sized nanosheets are less than $3 \mathrm{~nm}$ thick, containing $\mathrm{O} / \mathrm{N}$ heteroatoms and displaying amorphous structure. The energy released from ignition can be further used to produce useful chemical work, such as the thermal decomposition of $\left(\mathrm{NH}_{4}\right)_{2} \mathrm{Cr}_{2} \mathrm{O}_{7}$ into $\mathrm{Cr}_{2} \mathrm{O}_{3}$ pigment and catalyst or the expansion of graphite bisulfate into absorbing and thermal insulating graphite foam. The present findings show that 1,3-cyclodienes are versatile precursors toward the hypergolic synthesis of carbon nanostructures at ambient conditions, thus expanding the arsenal of chemical reagents used in hypergolic materials synthesis. Although the majority of examples provided from our group so far pertain to carbon, hypergolic materials synthesis can be extended beyond carbon for the synthesis of inorganic materials as well. Future work is underway in this direction using suitable organometallic compounds and fuming nitric acid as the starting reagents.

Author Contributions: Conceptualization, A.B.B.; methodology, N.C., A.B.B.; D.M., A.A., M.A.K. and D.G.; validation, N.C., A.B.B., D.M., A.A., M.A.K., and D.G.; investigation, N.C., A.B.B., D.M., K.S., K.C.V., A.A., M.A.K. and D.G.; data curation, N.C., A.B.B., D.M., A.A., M.A.K. and D.G.; writing-original draft preparation, N.C. and A.B.B.; writing-review and editing, N.C., A.B.B. and D.G.; supervision, A.B.B. and D.G. All authors have read and agreed to the published version of the manuscript.

Funding: We acknowledge the support of this work by the project "National Infrastructure in Nanotechnology, Advanced Materials and Micro-/Nanoelectronics" (MIS-5002772), which was implemented under the action "Reinforcement of the Research and Innovation Infrastructure", funded by the Operational Programme "Competitiveness, Entrepreneurship and Innovation" (NSRF 2014-2020), and co-financed by Greece and the European Union (European Regional Development Fund). N.C. gratefully acknowledges the IKY foundation for the financial support. This research was also co-financed by Greece and the European Union (European Social Fund- ESF) through the Operational Programme "Human Resources Development, Education and Lifelong Learning" in the context of the project "Strengthening Human Resources Research Potential via Doctorate Research" (MIS-5000432), implemented by the State Scholarships Foundation (IKY).

Institutional Review Board Statement: Not applicable.

Informed Consent Statement: Not applicable.

Data Availability Statement: The data presented in this study are available on request from the corresponding author.

Conflicts of Interest: The authors declare no conflict of interest.

\section{References}

1. Georgakilas, V.; Perman, J.A.; Tucek, J.; Zboril, R. Broad Family of Carbon Nanoallotropes: Classification, Chemistry, and Applications of Fullerenes, Carbon Dots, Nanotubes, Graphene, Nanodiamonds, and Combined Superstructures. Chem. Rev. 2015, 115, 4744-4822. [CrossRef] [PubMed]

2. Hirsch, A. The era of carbon allotropes. Nat. Mater. 2010, 9, 868-871. [CrossRef] [PubMed]

3. Fan, H.; Shen, W. Carbon Nanosheets: Synthesis and Application. ChemSusChem 2015, 8, 2004-2027. [CrossRef] [PubMed]

4. He, Y.; Zhuang, X.; Lei, C.; Lei, L.; Hou, Y.; Mai, Y.; Feng, X. Porous carbon nanosheets: Synthetic strategies and electrochemical energy related applications. Nano Today 2019, 24, 103-119. [CrossRef]

5. Schneider, S.; Hawkins, T.; Rosander, M.; Vaghjiani, G.; Chambreau, S.; Drake, G. Ionic Liquids as Hypergolic Fuels. Energy Fuels 2008, 22, 2871-2872. [CrossRef]

6. Yuan, W.-L.; Zhang, L.; Tao, G.-H.; Wang, S.-L.; Wang, Y.; Zhu, Q.-H.; Zhang, G.-H.; Zhang, Z.; Xue, Y.; Qin, S.; et al. Designing high-performance hypergolic propellants based on materials genome. Sci. Adv. 2020, 6, eabb1899. [CrossRef]

7. Elzein, B.; Jobin, O.; Robert, E. Reducing the Ignition Delay of Hypergolic Hybrid Rocket Fuels. J. Propuls. Power 2021, 37, $77-85$. [CrossRef]

8. Pfeil, M.A.; Dennis, J.D.; Son, S.F.; Heister, S.D.; Pourpoint, T.L.; Ramachandran, P.V. Characterization of Ethylenediamine Bisborane as a Hypergolic Hybrid Rocket Fuel Additive. J. Propuls. Power 2015, 31, 365-372. [CrossRef]

9. Baikousi, M.; Chalmpes, N.; Spyrou, K.; Bourlinos, A.B.; Avgeropoulos, A.; Gournis, D.; Karakassides, M.A. Direct production of carbon nanosheets by self-ignition of pyrophoric lithium dialkylamides in air. Mater. Lett. 2019, 254, 58-61. [CrossRef] 
10. Chalmpes, N.; Spyrou, K.; Bourlinos, A.B.; Moschovas, D.; Avgeropoulos, A.; Karakassides, M.A.; Gournis, D. Synthesis of Highly Crystalline Graphite from Spontaneous Ignition of In Situ Derived Acetylene and Chlorine at Ambient Conditions. Molecules 2020, 25, 297. [CrossRef] [PubMed]

11. Chalmpes, N.; Asimakopoulos, G.; Spyrou, K.; Vasilopoulos, K.C.; Bourlinos, A.B.; Moschovas, D.; Avgeropoulos, A.; Karakassides, M.A.; Gournis, D. Functional Carbon Materials Derived through Hypergolic Reactions at Ambient Conditions. Nanomaterials 2020, 10, 566. [CrossRef]

12. Chalmpes, N.; Spyrou, K.; Vasilopoulos, K.C.; Bourlinos, A.B.; Moschovas, D.; Avgeropoulos, A.; Gioti, C.; Karakassides, M.A.; Gournis, D. Hypergolics in Carbon Nanomaterials Synthesis: New Paradigms and Perspectives. Molecules 2020, $25,2207$. [CrossRef] [PubMed]

13. Chalmpes, N.; Tantis, I.; Bakandritsos, A.; Bourlinos, A.B.; Karakassides, M.A.; Gournis, D. Rapid Carbon Formation from Spontaneous Reaction of Ferrocene and Liquid Bromine at Ambient Conditions. Nanomaterials 2020, 10, 1564. [CrossRef] [PubMed]

14. Chalmpes, N.; Bourlinos, A.B.; Šedajová, V.; Kupka, V.; Moschovas, D.; Avgeropoulos, A.; Karakassides, M.A.; Gournis, D. Hypergolic Materials Synthesis through Reaction of Fuming Nitric Acid with Certain Cyclopentadienyl Compounds. C-J. Carbon Res. 2020, 6, 61. [CrossRef]

15. Chalmpes, N.; Bourlinos, A.B.; Talande, S.; Bakandritsos, A.; Moschovas, D.; Avgeropoulos, A.; Karakassides, M.A.; Gournis, D. Nanocarbon from Rocket Fuel Waste: The Case of Furfuryl Alcohol-Fuming Nitric Acid Hypergolic Pair. Nanomaterials 2021, 11, 1. [CrossRef] [PubMed]

16. Chalmpes, N.; Moschovas, D.; Tantis, I.; Bourlinos, A.B.; Bakandritsos, A.; Fotiadou, R.; Patila, M.; Stamatis, H.; Avgeropoulos, A.; Karakassides, M.A.; et al. Carbon Nanostructures Derived through Hypergolic Reaction of Conductive Polymers with Fuming Nitric Acid at Ambient Conditions. Molecules 2021, 26, 1595. [CrossRef] [PubMed]

17. Roh, J.-S. Structural Study of the Activated Carbon Fiber using Laser Raman Spectroscopy. Carbon Lett. 2008, 9, 127-130. [CrossRef]

18. Tsirka, K.; Katsiki, A.; Chalmpes, N.; Gournis, D.; Paipetis, A.S. Mapping of Graphene Oxide and Single Layer Graphene Flakes-Defects Annealing and Healing. Front. Mater. 2018, 5, 5. [CrossRef]

19. Bourlinos, A.B.; Giannelis, E.P.; Sanakis, Y.; Bakandritsos, A.; Karakassides, M.; Gjoka, M.; Petridis, D. A graphite oxide-like carbogenic material derived from a molecular precursor. Carbon 2006, 44, 1906-1912. [CrossRef]

20. Kouloumpis, A.; Thomou, E.; Chalmpes, N.; Dimos, K.; Spyrou, K.; Bourlinos, A.B.; Koutselas, I.; Gournis, D.; Rudolf, P. Graphene/Carbon Dot Hybrid Thin Films Prepared by a Modified Langmuir-Schaefer Method. ACS Omega 2017, 2, 2090-2099. [CrossRef]

21. Chalmpes, N.; Kouloumpis, A.; Zygouri, P.; Karouta, N.; Spyrou, K.; Stathi, P.; Tsoufis, T.; Georgakilas, V.; Gournis, D.; Rudolf, P. Layer-by-Layer Assembly of Clay-Carbon Nanotube Hybrid Superstructures. ACS Omega 2019, 4, 18100-18107. [CrossRef] [PubMed]

22. Potsi, G.; Bourlinos, A.B.; Mouselimis, V.; Poláková, K.; Chalmpes, N.; Gournis, D.; Kalytchuk, S.; Tomanec, O.; Błoński, P.; Medved', M.; et al. Intrinsic photoluminescence of amine-functionalized graphene derivatives for bioimaging applications. Appl. Mater. Today 2019, 17, 112-122. [CrossRef]

23. Rommozzi, E.; Zannotti, M.; Giovannetti, R.; D’Amato, C.A.; Ferraro, S.; Minicucci, M.; Gunnella, R.; Di Cicco, A. Reduced Graphene Oxide/TiO2 Nanocomposite: From Synthesis to Characterization for Efficient Visible Light Photocatalytic Applications. Catalysts 2018, 8, 598. [CrossRef]

24. Zhang, L.; Hu, N.; Yang, C.; Wei, H.; Yang, Z.; Wang, Y.; Wei, L.; Zhao, J.; Xu, Z.J.; Zhang, Y. Free-standing functional graphene reinforced carbon films with excellent mechanical properties and superhydrophobic characteristic. Compos. Part A Appl. Sci. Manuf. 2015, 74, 96-106. [CrossRef]

25. Spyrou, K.; Calvaresi, M.; Diamanti, E.K.; Tsoufis, T.; Gournis, D.; Rudolf, P.; Zerbetto, F. Graphite Oxide and Aromatic Amines: Size Matters. Adv. Funct. Mater. 2015, 25, 263-269. [CrossRef]

26. Grzyb, B.; Gryglewicz, S.; Śliwak, A.; Díez, N.; Machnikowski, J.; Gryglewicz, G. Guanidine, amitrole and imidazole as nitrogen dopants for the synthesis of N-graphenes. RSC Adv. 2016, 6, 15782-15787. [CrossRef]

27. Tsoukatos, T.; Avgeropoulos, A.; Hadjichristidis, N.; Hong, K.; Mays, J.W. Model Linear Block Co-, Ter-, and Quaterpolymers of 1,3-Cyclohexadiene with Styrene, Isoprene, and Butadiene. Macromolecules 2002, 35, 7928-7935. [CrossRef]

28. Misichronis, K.; Rangou, S.; Avgeropoulos, A. Synthesis and Molecular and Morphological Characterization of Poly(pTrimethylsilyl Styrene) and Diblock Copolymers with Poly(1,3-Cyclohexadiene). Int. J. Polym. Anal. Charact. 2008, 13, 136-148. [CrossRef]

29. Misichronis, K.; Rangou, S.; Ashcraft, E.; Kumar, R.; Dadmun, M.; Sumpter, B.G.; Zafeiropoulos, N.E.; Mays, J.W.; Avgeropoulos, A. Synthesis, characterization (molecular-morphological) and theoretical morphology predictions of linear triblock terpolymers containing poly(cyclohexadiene). Polymer 2013, 54, 1480-1489. [CrossRef]

30. Misichronis, K.; Chen, J.; Kahk, J.K.; Imel, A.; Dadmun, M.; Hong, K.; Hadjichristidis, N.; Mays, J.W.; Avgeropoulos, A. Diblock copolymers of polystyrene-b-poly(1,3-cyclohexadiene) exhibiting unique three-phase microdomain morphologies. J. Polym. Sci. Part B Polym. Phys. 2016, 54, 1564-1572. [CrossRef]

31. Misichronis, K.; Chen, J.; Imel, A.; Kumar, R.; Thostenson, J.; Hong, K.; Dadmun, M.; Sumpter, B.G.; Kennemur, J.G.; Hadjichristidis, N.; et al. Investigations on the Phase Diagram and Interaction Parameter of Poly(styrene-b-1,3-cyclohexadiene) Copolymers. Macromolecules 2017, 50, 2354-2363. [CrossRef] 